Article

\title{
The Effect of Thermo-Chemical Treatment on the Water Resistance of Defatted Soybean Flour-Based Wood Adhesive
}

\author{
Binghan Zhang ${ }^{1}$, Jin Li ${ }^{1}$, Yufei Kan ${ }^{1}$, Jianfang Gao ${ }^{1}$, Yuehong Zhang ${ }^{1,2, *(1)}$ \\ and Zhenhua Gao ${ }^{1, * \text { (D) }}$ \\ 1 College of Material Science and Engineering, Northeast Forestry University, Harbin 150000, China; \\ 18346186030@163.com (B.Z.); zyh6525069@126.com (J.L.); elevenzbh@aliyun.com (Y.K.); \\ shancr@aliyun.com (J.G.) \\ 2 College of Bioresources Chemical and Materials Engineering, Shaanxi University of Science and Technology, \\ Xi'an 710021, China \\ * Correspondence: zhangyuehong.nefu@gmail.com (Y.Z.); gaozh1976@163.com (Z.G.); \\ Tel.: +86-451-8219-2860 (Z.G.)
}

Received: 2 August 2018; Accepted: 22 August 2018; Published: 28 August 2018

\begin{abstract}
The aim of this study was to effectively improve the water resistance of a defatted soybean flour (DSF)-based adhesive by subjecting DSF to thermo-chemical treatment in the presence of sodium dodecyl sulfate (SDS), and then the crosslinking with epichlorohydrin-modified polyamide (EMPA). The effect of thermo-chemical treatment on the structures and properties of the DSF and DSF-based adhesive were investigated by plywood evaluation, boiling-water-insoluble content, and acetaldehyde value measurements, as well as FTIR, X-ray photoelectron spectroscopic (XPS), X-ray diffraction spectroscopy (XRD), thermogravimetric analysis (TGA), and rheology analyses. The test results revealed that the water resistance of the DSF-based adhesive was significantly improved, attributed to the formation of a solid three-dimensional crosslinked network structure resulted from the repolymerization of DSF, the Maillard reaction between the protein and carbohydrate, and chemical crosslinking between the crosslinker and DSF. Moreover, SDS destroyed the hydrophobic interactions within protein and inhibited macromolecular aggregations during the thermal treatment. Therefore, more reactive groups buried within the globular structure of the soybean protein component of DSF could be released, which supported the repolymerization, Maillard reaction, and chemical crosslinking of DSF, thereby leading to an improved crosslinking density of the cured DSF-based adhesive. In addition, the adhesive composed of thermo-chemically treated DSF and EMPA exhibited preferable viscosity and viscosity stability suitable for the production of wood composites.
\end{abstract}

Keywords: defatted soybean flour; thermo-chemical treatment; wood adhesive; sodium dodecyl sulfate (SDS); water resistance

\section{Introduction}

Formaldehyde-based adhesives are widely used in the timber industry due to their acceptable water resistance, durable adhesion performance, and low price [1]. However, these adhesives are mainly derived from non-renewable petroleum resources and contain a formaldehyde component that is considered to be a potential human carcinogen $[2,3]$. Therefore, there is a great demand for the development of safe and environmentally friendly wood adhesives. Defatted soybean flour (DSF), a byproduct of the soybean oil industry, is one of the most promising raw material alternatives for the development of wood adhesives. Thus, DSF is being increasingly used in the wood adhesive 
industry in China over the past few years due to its abundance, low cost, and renewability. However, the widespread application of traditional DSF-based adhesives is limited due to their poor water resistance and high viscosity [4].

DSF is a complex material comprising approximately $50 \%$ protein, $40 \%$ soybean carbohydrate, and other minor components [5]. The soybean protein component of DSF has complicated and diverse primary, secondary, tertiary, and quaternary structures, which are mainly built by weak intermolecular interactions, including hydrogen bonds, electrostatic bonds, Van der Waals forces, disulfide bonds, and hydrophobic interactions, leading to low reactivity and poor water resistance [6]. Most of the soybean carbohydrates within DSF are highly hydrophilic polysaccharides that decrease the water resistance of DSF-based adhesives. Many attempts have been made to improve the water resistance of DSF-based adhesives by the modification of DSF, including physical, chemical crosslinking, and biomimetic modification [7-11]. However, most reported modification strategies have focused on the modification of the protein component, which can be divided into two categories. The first category involves protein denaturation using chemical agents or physical means to unfold the protein structure and expose the reactive functional groups $\left(-\mathrm{NH}_{2},-\mathrm{COOH},-\mathrm{OH}\right.$, and $\left.-\mathrm{SH}\right)$. This allows the functional groups to interact with wood, thereby improving the adhesion strength $[12,13]$. The second category comprises crosslinking modifications by mixing DSF with reactive crosslinkers and/or small synthetic pre-polymers such as glyoxal [14], glutaraldehyde [15], methenamine, genipin [16], polyisocyanates [14,17], modified polyamides [18], epoxy resin [19], phenol-formaldehyde [20], and melamine-urea-formaldehyde [21]. These crosslinkers can react with the reactive groups in DSF and increase the crosslinking density of the corresponding DSF-based adhesive during the hot-press process. On the other hand, the synthetic pre-polymers react with the DSF components to form three-dimensional or interpenetrating network structures that increase the cohesion strength and effectively prevent moisture from intruding into the cured DSF-based adhesives [22]. Some of the above-mentioned modification methods significantly improve the water resistance of DSF-based adhesives. Thus, these adhesives can withstand hydrothermal testing (soaking in water at $63^{\circ} \mathrm{C}$ and boiling point). However, studies on the improvement of the water resistance of DSF-based adhesives by modification of the soybean carbohydrate component are scarce [23].

A soybean protein isolate (SPI)-based adhesive with good water resistance was recently developed using a combination of activation and chemical crosslinking modifications [6,24]. Activation modification was carried out by thermo-chemical treatment of the SPI at $120{ }^{\circ} \mathrm{C}$ for $0.5 \mathrm{~h}$ in the presence of protein-denaturing agents such as hydrochloric acid, sodium sulfite, SDS, and their combination. These denaturing agents unfolded and stretched the compact globular structure of the SPI by destroying its hydrogen and disulfide bonds, and its hydrophobic moieties. This was beneficial to the repolymerization of the SPI molecules and the exposure of the reactive groups buried in the globular structure of the SPI after thermo-chemical treatment. Thus, the thermo-chemically treated SPI could be crosslinked more sufficiently in the subsequent chemical crosslinking modification by epichlorohydrin-modified polyamide (EMPA) to form three-dimensional crosslinked network structures and convert the hydrophilic groups into hydrophobic structures. Consequently, the combination of SPI repolymerization after thermo-chemical treatment and the increased crosslinking efficiency between the SPI and crosslinker led to a significant improvement in the water resistance of the resultant adhesive [24], which could withstand a $28 \mathrm{~h}$ boiling-dry-boiling hydrothermal treatment and maintain a hydrothermal-aged wet bond strength up to $1.22 \mathrm{MPa}$ (exceeding the required value of $0.98 \mathrm{MPa}$ for structural use), as presented in Figure 1.

However, its high cost has made SPI less attractive as a starting material for the preparation of wood adhesive. DSF, a by-product of the soybean oil industry that is mainly used as animal feed with low added value, costs a fraction $(1 / 4$ to $1 / 5)$ of the cost of SPI [25]. Thus, it is considered one of the most promising candidates for the preparation of wood adhesives. To develop a low-cost soybean-based adhesive with the desired water resistance using DSF, this work investigated the effect of thermo-chemical treatment on the properties of DSF and DSF-based adhesives. Notably, 
the Maillard reaction is a complex set of reactions that takes place between proteins and carbonyl compounds including soybean carbohydrate at high temperatures [5]. Thus, the interactions between the soybean carbohydrate and protein component within DSF during thermo-chemical treatment were also investigated $[23,26]$. Therefore, changes in the functional groups, secondary structure, water solubility, reactivity, crystallinity, and thermo-stability of DSF, before and after thermo-chemical treatment, were evaluated to elucidate the improvement mechanism of the water resistance of DSF-based adhesives.

\section{Materials and Methods}

\subsection{Materials}

DSF, with an average protein content of $53.4 \%$, and SPI, with a protein content of $93.4 \mathrm{wt} \%$, (particle size $<0.096 \mathrm{~mm}$ ) were purchased from Harbin High-Tech Soybean Food Co., Ltd., Harbin, China. EMPA aqueous solution was synthesized in our lab using diethylenetriamine, adipic acid, and epichlorohydrin, which had a solid content of $13.8 \%, \mathrm{pH}$ of 2.6 , and a viscosity of $96.4 \mathrm{mPa} . \mathrm{s}\left(25^{\circ} \mathrm{C}\right)$. Diethylenetriamine, adipic acid, and epichlorohydrin were obtained from local chemical companies, Harbin, China. Reagent-grade SDS (with a content of 99.5\%) was purchased from Tianjin Kermel Chemical Reagent Co., Ltd., Tianjin, China. Birch veneers, with dimensions of $420 \mathrm{~mm} \times 420 \mathrm{~mm} \times 1.6 \mathrm{~mm}$ and moisture content of $8-10 \%$, were supplied by a local plywood plant in Harbin.

\subsection{Thermo-Chemical Treatment of DSF}

About $100 \mathrm{~g}$ DSF was blended with $35 \mathrm{~g}$ of a solution containing $2.5 \mathrm{~g}$ SDS in a high-speed mixer at $800 \mathrm{rpm}$. After uniform mixing, the mixture was placed on a polytetrafluoroethylene film to form a thin layer. This was then placed in an oven preheated at $140{ }^{\circ} \mathrm{C}$ for $30 \mathrm{~min}$. After cooling to room temperature, the product was ground to a fine powder, passed through a 120-mesh sieve, and marked as TDS-SDS. SPI was also thermo-chemically treated as that of TDS-SDS by just replacing DSF by SPI (labeled TSP-SDS). Native DSF and DSF that were thermally treated without using SDS were selected as the controls and labeled DSF and TDS, respectively.

\subsection{Preparation of the DSF-Based Adhesives and Cured Samples}

The DSF-based adhesives were prepared by mechanically blending 40 parts soybean flour powder (TDS-SDS, DSF, and TDS) with 100 parts liquid EMPA solution by mass, at room temperature, until no particle clusters were observed. These samples were labeled "TDS-SDS+EMPA", "DSF+EMPA", and "TDS+EMPA", respectively.

About $5 \mathrm{~g}$ of the above prepared DSF-based adhesives were then placed in a polytetrafluoroethylene container and cured at $120-125^{\circ} \mathrm{C}$ for $2 \mathrm{~h}$ to produce the cured DSF-based adhesive samples (with curing reactions illustrated in Figure 3). After cooling to room temperature, these samples were ground to a fine powder and passed through a 160-mesh sieve prior to characterization.

\subsection{Bond Strength and Water Resistance by Plywood Evaluation}

Three-ply plywood panels were fabricated with liquid adhesive loadings of $180 \mathrm{~g} / \mathrm{m}^{2}$ (single glue line) by coating the adhesive onto both faces of the core veneer. Two face veneers without adhesive and an adhesive-coated veneer were stacked by hand with their grains vertical to each other. The stacks were then cold pressed at $1.1 \mathrm{MPa}$ and room temperature for $45 \mathrm{~min}$ and finally hot pressed at $120^{\circ} \mathrm{C}$ and 1.3 MPa for $4 \mathrm{~min}$. After hot pressing, the panels were stored under a $20-25^{\circ} \mathrm{C}$ and $40-60 \mathrm{RM} \%$ chamber for $\geq 24 \mathrm{~h}$ prior to testing. A total of 40 specimens with a glued area of $25 \mathrm{~mm} \times 25 \mathrm{~mm}$ were cut according to the commercial standard JIS K6806-2003 to determine the bond strength (20 specimens) and water resistance (or bond durability, 20 specimens), in terms of the dry strength and aged wet 
strength, respectively, by a tensile shear mode. The test was performed using a tensile testing machine with a crosshead speed of $5 \mathrm{~mm} / \mathrm{min}$. The specimens for the aged wet strength test underwent a $28 \mathrm{~h}$ boiling-dry-boiling treatment ( $4 \mathrm{~h}$ of boiling, $20 \mathrm{~h}$ of oven-drying at $63 \pm 2{ }^{\circ} \mathrm{C}$, and $4 \mathrm{~h}$ of boiling), were cooled to room temperature, and subsequently measured under wet state [27]. In contrast, the specimens for the dry bond strength tests were measured under dry state.

\subsection{Water-Insoluble Content Determination of DSF, TDS, TDS-SDS, and Their Corresponding Cured Adhesives}

Approximately $2.0 \mathrm{~g}$ sample (DSF, TDS, TDS-SDS, and their corresponding cured adhesives; passed through a 160 -mesh sieve, $W_{0}$, accurate to $0.0001 \mathrm{~g}$ ), and $200.0 \mathrm{~g}$ distilled water were added in a $250 \mathrm{~mL}$ flask equipped with mechanical stirring and refluxing equipment. The mixture was stirred and boiled for $4 \mathrm{~h}$. The afforded dispersion was cooled to room temperature and filtered, and the collected residue was rinsed twice with $50 \mathrm{~mL}$ distilled water. The glass-filter paper was dried to constant weight ( $\mathrm{W}_{1}$, accurate to $0.0001 \mathrm{~g}$ ) in advance. The glass-filter paper including filtered residue was oven-dried at $120^{\circ} \mathrm{C}$ to constant weight $\left(W_{2}\right.$, accurate to $\left.0.0001 \mathrm{~g}\right)$. The boiling-water-insoluble content was defined as the mass percentage of test sample insoluble in boiling water and calculated as $\left[\left(W_{2}-W_{1}\right) / W_{0}\right] \times 100 \%$.

\subsection{Acetaldehyde Value of DSF, TDS, and TDS-SDS}

A $100 \mathrm{~mL}$ reaction flask equipped with a mechanical stirrer, thermostat, and condenser (Lichen, Shanghai, China) for reflux was charged with approximately $1.5 \mathrm{~g}$ sample (DSF, TDS, and TDS-SDS; particle size, passed through a 160-mesh sieve; $m_{1}$, accurate to $0.0001 \mathrm{~g}$ ), $50.0 \mathrm{~mL}$ water, and $5.0 \mathrm{~mL}$ of $40 \mathrm{wt} \%$ acetaldehyde. The $\mathrm{pH}$ of the mixture was adjusted to $8.5-8.7 \mathrm{using}$ a $20 \mathrm{wt} \%$ sodium hydroxide solution. The mixture was then maintained at $50 \pm 2{ }^{\circ} \mathrm{C}$ for $120 \mathrm{~min}$, subsequently allowed to cool to room temperature, and then filtered. The residue was rinsed twice with $50 \mathrm{~mL}$ distilled water. All the filtered solutions, including the rinsed solution, were diluted to $1000 \mathrm{~mL}$ in a volumetric flask. The unreacted acetaldehyde content in the diluted filtrate $\left(F_{1}, \mathrm{mmol} / \mathrm{L}\right)$ was tested according to the test method for free formaldehyde described in the literature [24]. The test was repeated in triplicate. Three blank tests were also conducted under the same conditions, without the addition of DSF, to determine the total free acetaldehyde content $\left(F_{0}, \mathrm{mmol} / \mathrm{L}\right)$ prior to the reaction. The acetaldehyde value $(\mathrm{mg} / \mathrm{g})$ of the sample was defined as the equivalent mass of acetaldehyde $(\mathrm{mg})$ that can react with $1 \mathrm{~g}$ solid DSF, calculated as $\left[\left(F_{0}-F_{1}\right) \times 44\right] / m_{1}$.

\subsection{X-ray Photoelectron Spectroscopic (XPS) Analysis}

The surface chemical compositions of the native DSF, TDS, and TDS-SDS samples were analyzed using a K $\alpha$ X-ray photoelectron spectrometer (Thermo Fisher Scientific Inc., Waltham, MA, USA) with monochromatic Al-K $\alpha$ radiation at $100 \mathrm{~W}$. High-energy photoemission spectra (Thermo Fisher Scientific Inc., Waltham, MA, USA) were recorded using a pass energy of $50 \mathrm{eV}$ and a resolution of $0.1 \mathrm{eV}$. Curve-fitting analysis of the $C_{1 \mathrm{~s}}$ peak was performed using the Gaussian-Lorentzian curve fitting function to result in the smallest least-square coefficient by XPS Peak 4.0 software.

\subsection{FT-IR Analysis}

Structural changes in the DSF, TDS, and TDS-SDS were observed using Fourier transform infrared (FTIR) spectroscopy (Nicolet Co., WI, USA; 4000-400 cm $\mathrm{cm}^{-1} 4 \mathrm{~cm}^{-1}$ resolution; 32 scans). The peak decomposition was performed in the region 1700-1600 $\mathrm{cm}^{-1}$ assigned to the amide I band of the soybean protein component. A second-derivative analysis was carried out to attain quantitative information about the secondary structures of the protein in DSF. Thus, after baseline correction, the Fourier self-deconvolution and the deconvoluted (differential) spectra were first resolved. Subsequently, the individual component bands were quantified according to a Gaussian curve fit (GCF). The procedure maintained the initial band positions at an interval of $4 \pm 1 \mathrm{~cm}^{-1}$, excluding bands with negative heights. It also retained the bandwidth within the expected limits in 
agreement with the theoretical boundaries and predictions. The relative amounts of the various DSF secondary structures were determined from the second derivative of the amide I band (areas under the bands assigned to a particular substructure). The difference between the measured spectrum and the curve fit was calculated as an internal control of the success of the curve fitting process.

\subsection{X-ray Diffraction Spectroscopy (XRD) Analysis}

The changes in crystalline structure of the native DSF, TDS, and TDS-SDS treated at various temperatures were recorded on a D/MAX-2200 diffractometer (Rigaku, Tokyo, Japan) using a Cu-K $\alpha$ source. Diffraction data were collected from $5^{\circ}$ to $50^{\circ}$ with a step interval of $0.02^{\circ}$, an accelerating voltage of $40 \mathrm{kV}$, and a current of $30 \mathrm{~mA}$.

\subsection{Thermogravimetric Analysis (TGA)}

Thermogravimetric analysis was performed on a TA Instruments Discovery (NETZSCH Co., Selb, Germany) TGA. All samples were tested from room temperature to $800^{\circ} \mathrm{C}$ at a scanning rate of $10{ }^{\circ} \mathrm{C} / \mathrm{min}$ under nitrogen $(25 \mathrm{~mL} / \mathrm{min})$.

\subsection{Dynamic Viscoelastic Measurements}

The apparent viscosity of the fresh DSF-based adhesives ("TDS-SDS+EMPA", "DSF+EMPA", and "TDS+EMPA") was determined using an AR 2000ex rheometer (TA Instruments Ltd., New Castle, DE, USA) with a parallel plate fixture (40 mm diameter with thermostat). The distance was set to $1.5 \mathrm{~mm}$ for all the measurements. The experiments were conducted under a steady shear flow at $25^{\circ} \mathrm{C}$ using two modes: A frequency mode (shear rate range $=0.1-600 \mathrm{~s}^{-1}$ in $10 \mathrm{~s}^{-1}$ increments), and a time mode that maintained the sample at a shear rate of $10 \mathrm{~s}^{-1}$ for $40 \mathrm{~min}$.

\subsection{Statistical Analysis}

The data in the current study were statistically evaluated using the statistical software package Minitab version 15 and reported as the mean value \pm standard deviation of the replicates. A single-factor analysis of variance was conducted to identify significant differences among mean values according to least significant difference criteria with a 95\% confidence level $(p<0.05)$.

\section{Results}

The bond strength and water resistance of the DSF-based adhesives are presented in Figure 1. The plywood bonded with the "DSF+EMPA" adhesive (formulated by native DSF and EMPA as the crosslinker) could withstand a $28 \mathrm{~h}$ boiling-dry-boiling hydrothermal test; however, the aged wet bond strength could not meet the required value $(0.98 \mathrm{MPa})$ for structural use according to the commercial standard JIS K6806-2003. This was mainly attributed to the most reactive groups $\left(-\mathrm{NH}_{2},-\mathrm{OH}\right.$, and $\left.-\mathrm{COOH}\right)$ of the DSF protein component being buried within the highly ordered and compact globular structure. This leads to insufficient contact area with the wood surface, an undesired protein-wood interface, and limited reactive sites for potential adsorption interactions and chemical reactions. As expected, the plywood bonded with the "TDS-SDS+EMPA" adhesive, formulated by thermo-chemically treated DSF in the presence of SDS, exhibited superior water resistance over that of the control adhesive "DSF+EMPA." This was confirmed by the $73 \%$ increase in the aged wet bond strength of the "TDS-SDS+EMPA" adhesive over that of the control, which is almost the same as that of the "TSP-SDS+EMPA" adhesive (TSP-SDS refers to thermo-chemically treated SPI in the presence of SDS). These results indicated that similar to SPI, DSF could also be effectively activated by thermo-chemical treatment. In contrast, the "TDS+EMPA" adhesive, composed of sole thermo-chemically treated DSF without SDS, displayed a less improvement in water resistance than that observed for the "TDS-SDS+EMPA" adhesive. Moreover, the aged wet bond strength was only $26 \%$ higher than that of the control adhesive "DSF+EMPA." This confirmed that compared to sole 
thermal treatment, the thermo-chemical treatment of DSF in the presence of SDS could improve the water resistance of DSF-based adhesives more effectively.

Thermal treatment is often used to dissociate proteins into their constituent subunits, unfold their structure and surface, and therefore expose their hydrophilic groups to reactivity [28]. However, the high-temperature thermal treatment of DSF was usually accompanied by an aggregation of unfolded protein molecules [29]. Thus, some protein reactive groups were re-embedded, thereby leading to less crosslinking reactions between the protein and crosslinker. Consequently, the plywood bonded with the "TDS+EMPA" adhesive exhibited lower aged wet bond strength than that with the "TDS-SDS+EMPA" adhesive (Figure 1). This was attributed to a lower degree of crosslinking (Figure 2C) caused by less available reactive groups/sites (Figure 2A) compared to those present in the TDS-SDS sample.

SDS is a disperser that can unfold the globular structure of soybean proteins by destroying the hydrophobic moieties and exposing the buried reactive groups [13]. Moreover, it can bind strongly with the protein molecules through hydrophobic interactions. This increases the surface charge and intermolecular repulsion of the protein and therefore inhibits insoluble macromolecular aggregation [30]. As a result, the thermo-chemically treated TDS-SDS sample displayed a lower boiling-water-insoluble content (25\%) than that of the thermally treated TDS sample (35\%). However, both values were higher than that observed for the native DSF (22\%, Figure $2 \mathrm{~B})$. These results indicated that both the thermal and thermo-chemical treatments could lead to the repolymerization of the DSF components via the $-\mathrm{SH}$ and S-S interchange reactions and the Maillard reaction between the protein and carbohydrate at $140{ }^{\circ} \mathrm{C}$. Additionally, the presence of SDS could effectively inhibit macromolecular aggregation during thermal treatment.

The results presented in Figure $2 \mathrm{C}$ reveal that cured DSF based adhesives composed of TDS-SDS displayed a higher boiling-water-insoluble content $(72 \%)$ than that of the adhesive solely composed of TDS (69\%), suggesting that the "TDS-SDS+EMPA" adhesive had a higher crosslinking density than the "TDS+EMPA" adhesive. This was attributed to the release of more reactive groups, such as amino groups $\left(-\mathrm{NH}_{2}\right)$ after the DSF was thermo-chemically treated. These groups can react with the azetidinium groups of the EMPA crosslinker [31,32] (Figure 3), resulting in the formation of a dense and crosslinked network structure that prevents the invasion of water. The acetaldehyde value test in Figure 2A confirmed that more reactive amino groups were released after both thermal and thermo-chemical treatment. Because the consumption of acetaldehyde in the DSF-acetaldehyde system was attributed to the reactions between the acetaldehyde and amino groups of the soybean protein, the acetaldehyde value represented the number of amino groups that were able to react with the crosslinker in various DSF samples. A high acetaldehyde value suggested the presence of more crosslinking reactions between the DSF sample and the post-added EMPA crosslinker.

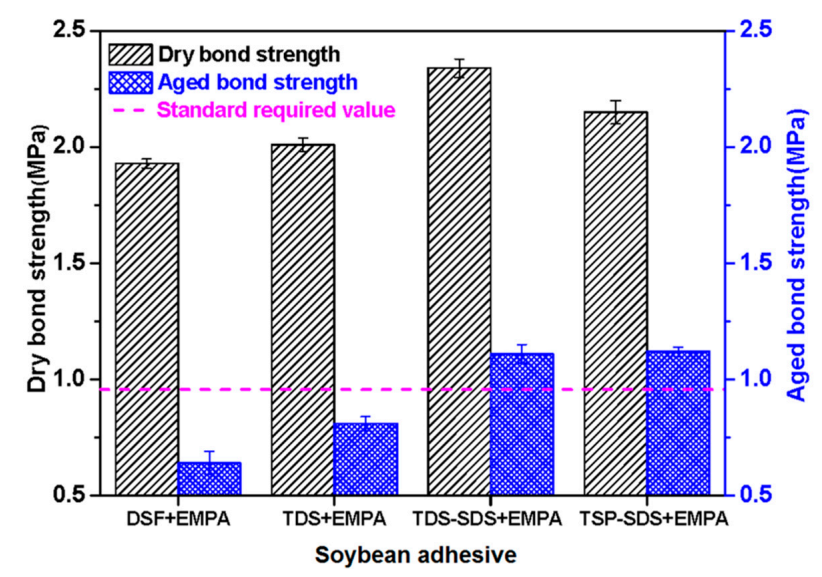

Figure 1. Bond properties of defatted soybean flour (DSF)-and soybean protein isolate (SPI)-based adhesives with various formulations. 


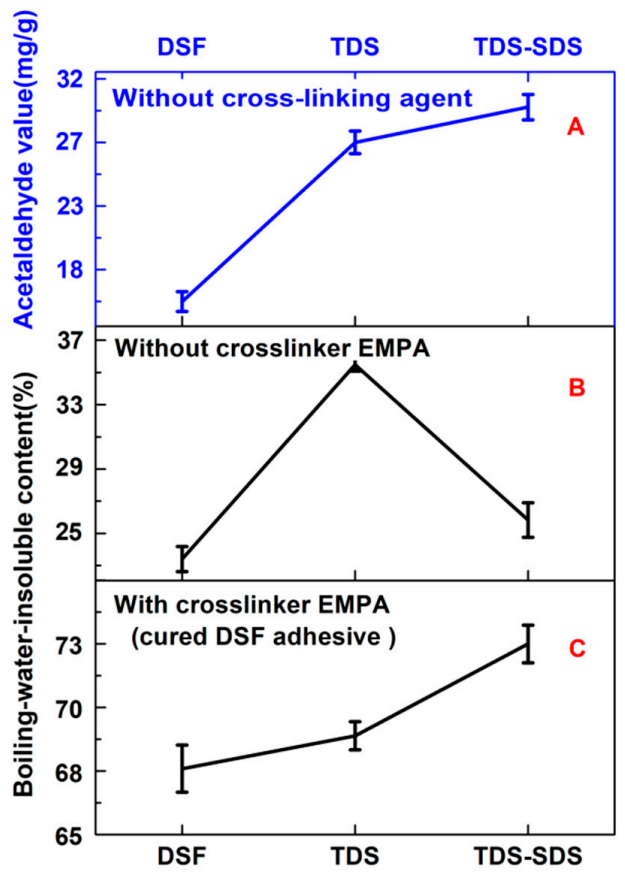

Figure 2. (A) Acetaldehyde values and (B,C) boiling-water-insoluble contents of various DSF samples.

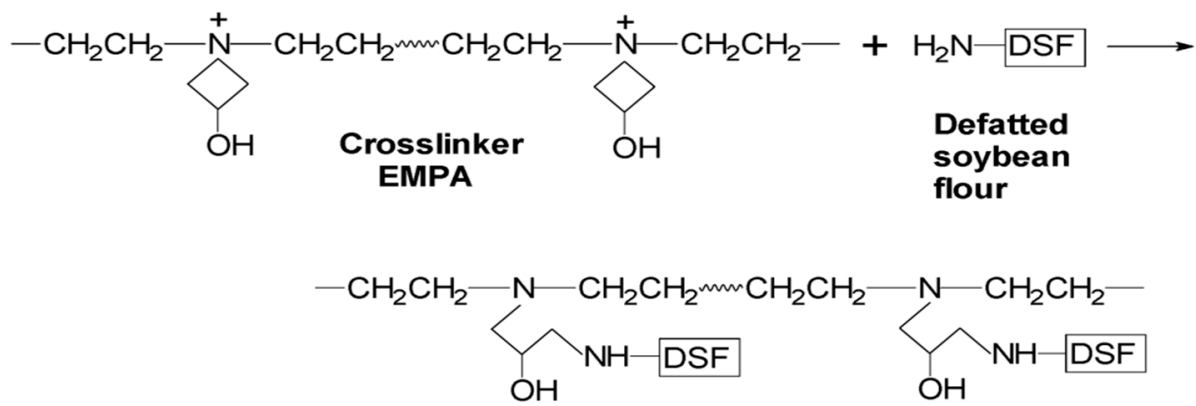

Figure 3. Schematic illustration of the crosslinking reaction between DSF and epichlorohydrin-modified polyamide (EMPA).

The optical photographs in Figure 4 illustrates that the colors of the DSF samples changed from grey to yellowish grey and light yellow after thermal and thermo-chemical treatment, respectively, indicating the occurrence of the Maillard reaction between the protein and the soybean carbohydrates. The Maillard reaction of DSF is related to a range of complex browning reactions between the protein amino groups and the carbohydrate carbonyl groups (such as aldehyde groups) upon heating. This reaction is generally accompanied by the consumption of amino groups and the formation of Amadori compounds (-C-O-), Schiff bases $(-\mathrm{C}=\mathrm{N}-)$, and pyrazines $(-\mathrm{C}-\mathrm{N}-)$ [33]. However, all the structures involved in the Maillard reaction were difficult to observe with FT-IR analysis (Figure 5) due to the overlap of their peaks in the fingerprint. No new IR absorption peaks were detected in the FT-IR spectra; however, the peak intensities at $1624 \mathrm{~cm}^{-1}$ (amide I, C=O stretching) and $1514 \mathrm{~cm}^{-1}$ (amide II, $\mathrm{N}-\mathrm{H}$ bending) decreased. This indicated a change in the concentration of these groups. These data confirmed that repolymerization of the soybean protein and the Maillard reaction between the protein and soybean carbohydrate within DSF occurred during the thermal and thermo-chemical treatment of DSF.

In XPS analysis, the C1s photoelectron peaks of DSF, TDS, and TDS-SDS were deconvoluted, according to results reported in the literature [34,35]: Peak $\mathrm{C} 1$ at $284.6 \mathrm{eV}$, corresponding to $\mathrm{C}-\mathrm{C}$ or $\mathrm{C}-\mathrm{H}$ bonds, indicates the presence of hydrophobic properties; peak $\mathrm{C} 2$ at $285.7 \mathrm{eV}$, corresponding 
to $\mathrm{C}-\mathrm{NH}-\mathrm{C}$, results from the reaction between the carbohydrate and protein; peak $\mathrm{C} 3$ at $286.4 \mathrm{eV}$, related to $\mathrm{C}-\mathrm{OH}$ which was derived from the carbohydrate, indicates the presence of hydrophilic properties; and peak $\mathrm{C} 4$ at $287.8 \mathrm{eV}$, assigned to $-\mathrm{CO}-\mathrm{NH}-$, results from the condensation reaction between the primary amine and carboxyl groups. The XPS data in Figure 4 and Table 1 reveal an increase in the areas of peaks $\mathrm{C} 2$ and $\mathrm{C} 4$ and the significant decrease in the area of Peak C3 after DSF underwent thermal and thermo-chemical treatment. These results indicate that a Maillard reaction occurred between the soybean protein and carbohydrate components. Because SDS favors the release of reactive amino groups during thermo-chemical treatment, TDS-SDS was more reactive and further supported the Maillard reaction between carbohydrates and protein, as confirmed by the marked decrease in the $\mathrm{NH}_{2}$ and $\mathrm{C}=\mathrm{O}$ IR absorption peaks in Figure 5. As the second largest component in DSF, soybean carbohydrates exhibited negative effects on the bond strength and water resistance of the adhesive. This was attributed to the increased water absorption due to the presence of abundant hydrophilic hydroxyl groups [24]. These data suggest that sufficient carbohydrate crosslinking via thermo-chemical treatment could effectively improve the water resistance of DSF-based adhesives. Moreover, these results are comparable to the results observed for the SPI-based adhesive (Figure 1).

The IR peak deconvolution of amide I ( $\mathrm{C}=\mathrm{O}$ stretching vibration) is presented in Figure 6. The areas of the assigned amide I bands in the second derivative spectra linearly correspond to the amount of the different types of secondary structures present in the protein [36]. The corresponding relationship between each sub-peak and the secondary structure were assigned as follows: The bands corresponding to the $\beta$-sheet appeared in the frequency regions $1610-1640 \mathrm{~cm}^{-1}$ and $1670-1690 \mathrm{~cm}^{-1}$, the $\beta$-turn appeared in the region $1660-1670 \mathrm{~cm}^{-1}$, the random coil structure appeared in the region $1640-1650 \mathrm{~cm}^{-1}$, and the $\alpha$-helix appeared in the region $1650-1660 \mathrm{~cm}^{-1}$ [36-38]. The $\alpha$-helix, $\beta$-turn, $\beta$-sheet, and unordered structure contents in DSF, TDS, and TDS-SDS are listed in Table 2. After thermal and thermo-chemical treatment, the $\beta$-sheet structure contents increased from $4 \%$ to $31 \%$ and $52 \%$, respectively, in accordance with the XRD results. The XRD peaks at $2 \theta$ of $9^{\circ}$ and $20^{\circ}$ belong to the $\alpha$-helix and $\beta$-sheet structures of the DSF soybean protein component, respectively (Figure 7). Compared to the values observed for DSF and TDS, the peak intensity of TDS-SDS at $2 \theta \approx 9^{\circ}$ decreased, whereas that at $2 \theta \approx 20^{\circ}$ increased. The $\beta$-sheet structure is an important form of protein secondary structure. An increased $\beta$-sheet content led to more regular peptide chains, attributed to the rearrangement of the hydrophobic chains formed in the hydrophobic regions. This indicated that the rearrangement of the protein molecules led to more regular protein structures in DSF after thermal and thermo-chemical treatment.

The repolymerization of the proteins, rearrangement of the protein hydrophobic chains, Maillard reaction between the protein and carbohydrate, and effective crosslinking reaction between TDS-SDS and EMPA led to the formation of a more compact network structure, as illustrated in Figure 8. Thus, all these factors contributed towards the improvement in the water resistance of the cured adhesive (TDS-SDS+EMPA). The TGA data in Figure 9 revealed that there are no significant differences in the main decomposition temperatures of the various cured adhesives. However, the adhesive "TDS-SDS+EMPA" displayed a slower and lower weight loss, indicating its improved thermal stability. This was attributed to the improved crosslinking density and more compact network structure of the cured adhesive.

Table 1. Structure contents of the defatted soybean flour (DSF), TDS, and TDS-sodium dodecyl sulfate (SDS) samples by X-ray photoelectron spectroscopic (XPS) analysis.

\begin{tabular}{ccccc}
\hline Samples & C-C (\%) & C-NH-C (\%) & C-OH (\%) & NH-CO (\%) \\
\hline DSF & 59 & 12 & 8 & 20 \\
TDS & 58 & 18 & 4 & 19 \\
TDS-SDS & 56 & 23 & 3 & 17 \\
\hline
\end{tabular}




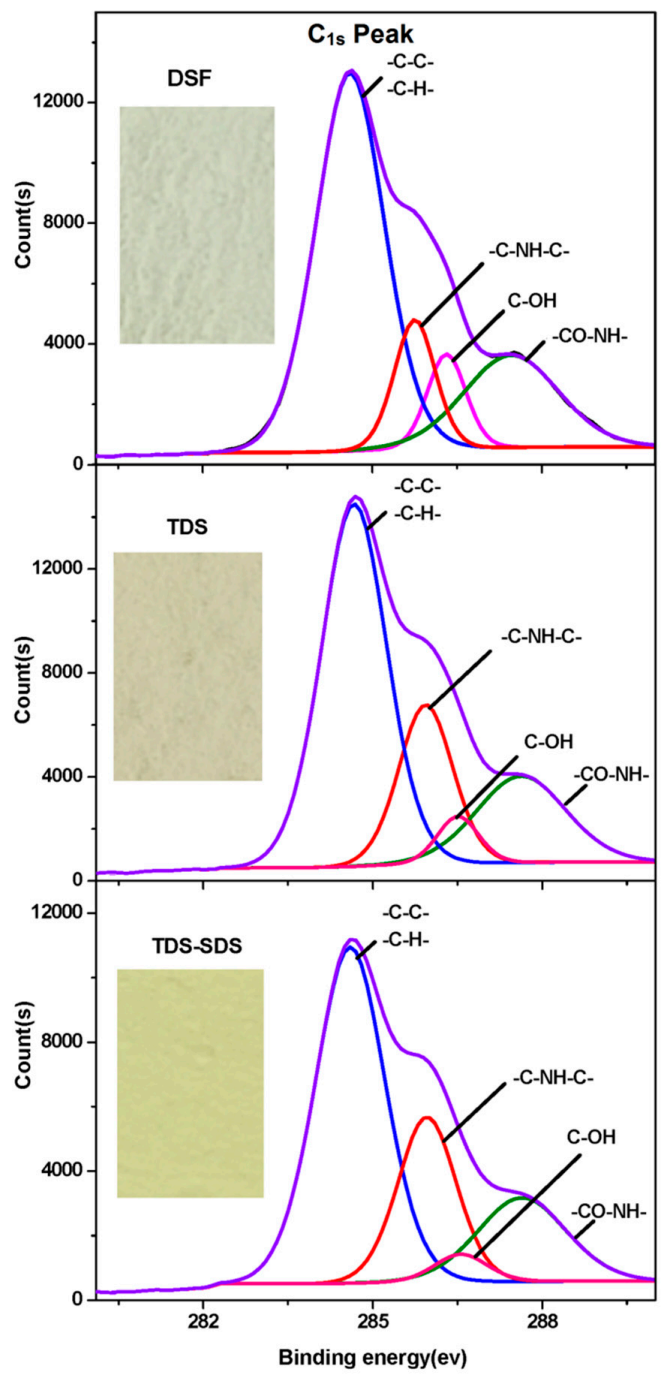

Figure 4. X-ray photoelectron spectroscopic (XPS) spectra and photographs of various DSF samples.

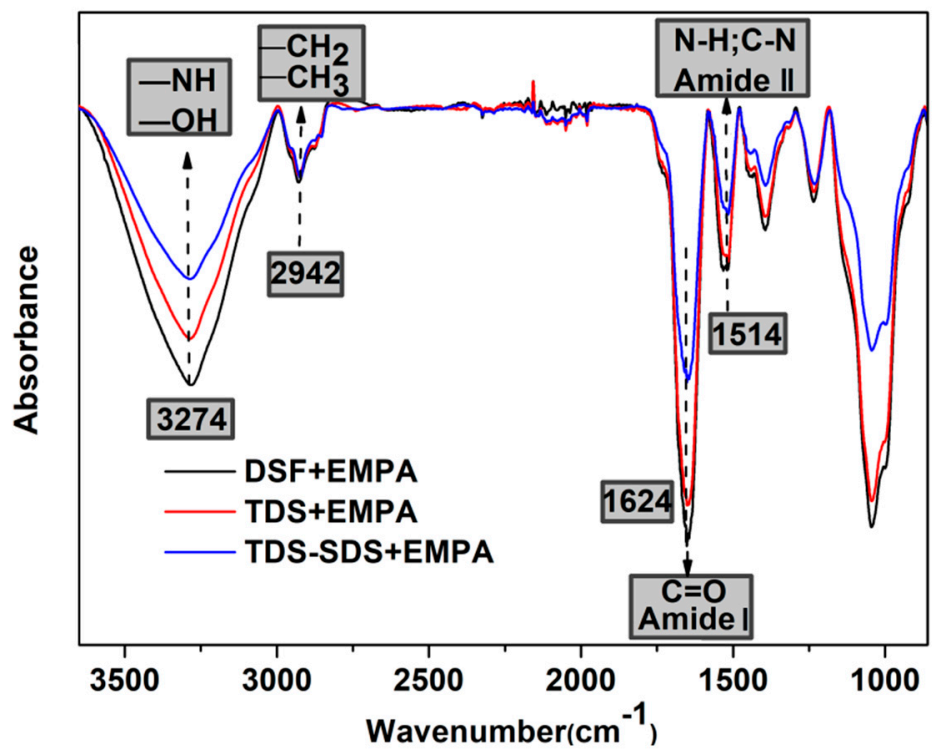

Figure 5. FT-IR spectra of various DSF-based adhesives. 


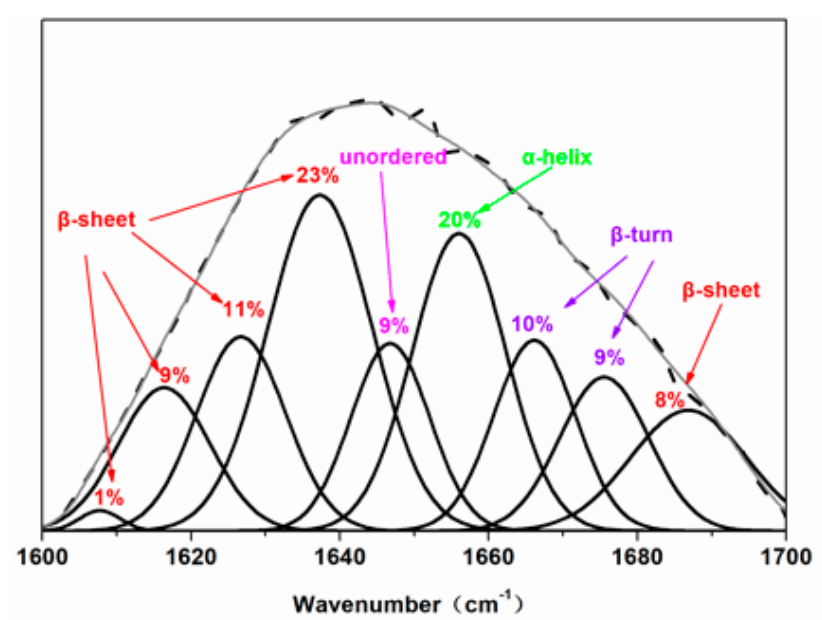

Figure 6. Deconvolution of the amide I spectra (continuous curve), the Gaussian curve fit (GCF) bands thereof (point line), and the second-derivative spectra of the TDS-sodium dodecyl sulfate (SDS) sample.

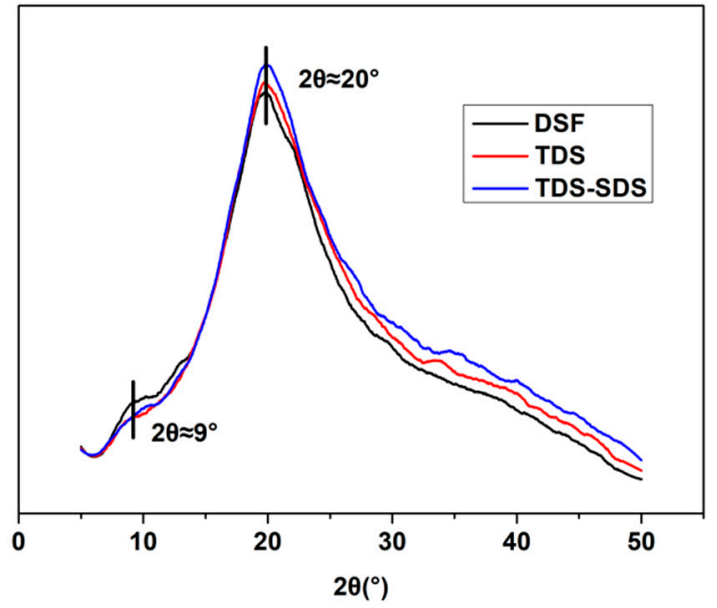

Figure 7. X-ray Diffraction Spectroscopy (XRD) patterns of various DSF samples.

Table 2. Secondary structure content in the DSF, TDS, and TDS-SDS samples.

\begin{tabular}{ccccc}
\hline Samples & $\boldsymbol{\beta}$-Sheet (\%) & Unordered (\%) & $\boldsymbol{\alpha}$-Helix (\%) & $\beta$-Turn (\%) \\
\hline DSF & 4 & 46 & 37 & 14 \\
TDS & 31 & 31 & 10 & 30 \\
TDS-SDS & 52 & 9 & 20 & 19 \\
\hline
\end{tabular}

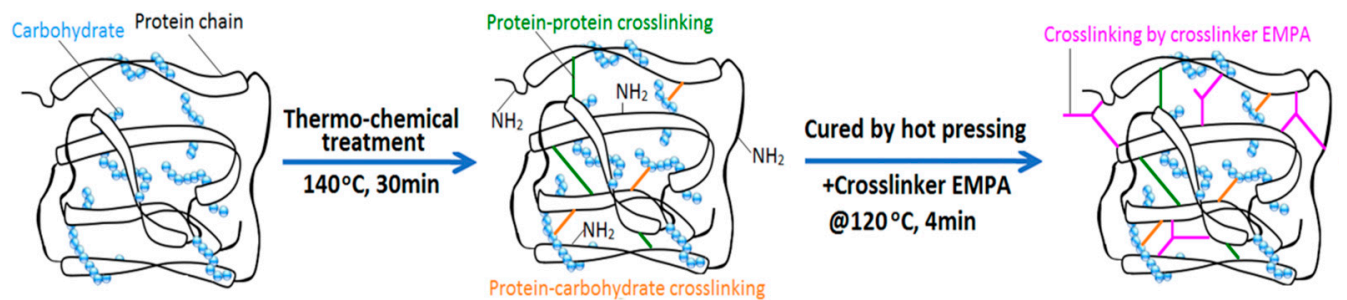

Figure 8. Schematic illustration of the crosslinking modes of TDS-SDS and its cured adhesive. 


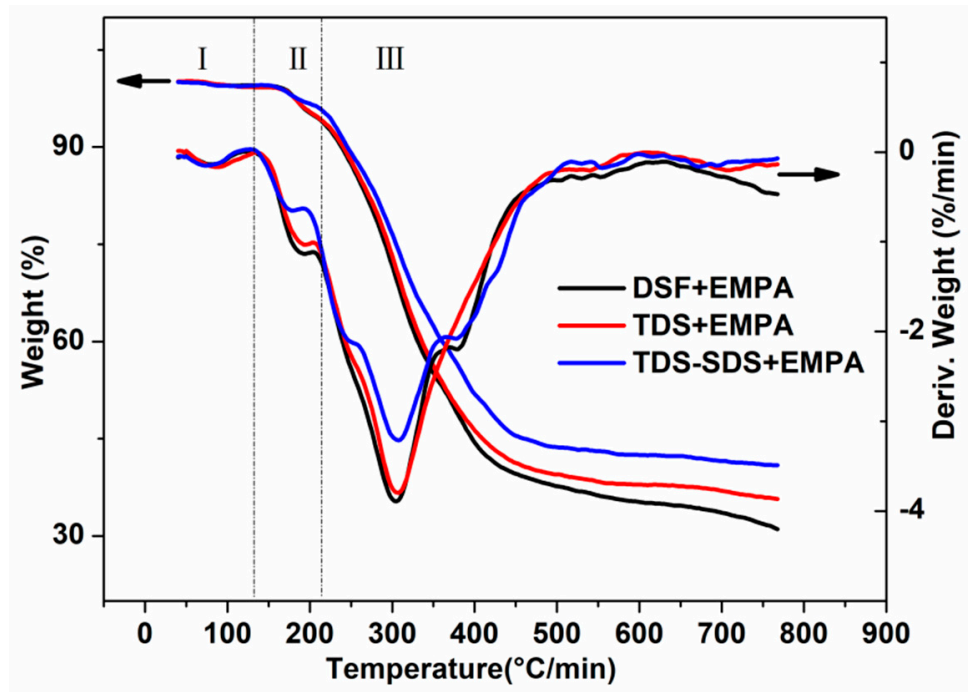

Figure 9. Thermogravimetric analysis (TGA) and DTG curves of various DSF-based adhesives.

Due to the higher protein content and large molecular weight of soybean protein, the TSP-SDS+EMPA adhesive composed of thermo-chemically treated SPI in the presence of SDS (TSP-SDS) and EMPA as the crosslinker ( $37 \mathrm{wt} \%$ solid content) displayed a viscosity between $6.86 \times 10^{4}$ and $7.02 \times 10^{4} \mathrm{mPa}$.s (BROOKFIELD DV-II+PRO viscometer at $25^{\circ} \mathrm{C}$ and $10 \mathrm{~s}^{-1}$ rotating speed). Thus, it was difficult to spread this SPI adhesive evenly onto the veneer. Moreover, the higher viscosity displayed negative effects on the wettability and penetration of the adhesive into the wood substrate. On the other hand, the viscosity of the DSF-based adhesive composed of TDS-SDS with the same solid content was much lower $\left(\sim 1.13 \times 10^{4} \mathrm{mPa}\right.$.s, by BROOKFIELD DV-II+PRO viscometer at $25^{\circ} \mathrm{C}$ and $10 \mathrm{~s}^{-1}$ rotating speed). Therefore, while displaying the improved bond strength and water resistance observed for the SPI-based adhesive, the DSF-based adhesive was easier to spread and supported wettability and penetration into the wood substrate (Figure 1). The apparent viscosities of the two DSF-based adhesives, determined by rheological testing, are presented in Figure 10.

In frequency mode, the apparent viscosities (Figure 10A) decreased as the shear rate increased from 0.1 to $300 \mathrm{~s}^{-1}$, revealing that the shear-thinning behaviors of the two DSF-based adhesives were similar to that of other reported soybean adhesives [39]. Although they displayed a similar decreasing tendency, the initial apparent viscosity of the "DSF+EMPA" adhesive was $38 \%$ greater than that of the "TDS-SDS+EMPA" adhesive. This increase indicated that in the EMPA solution, DSF disperses and then unfolds more easily than TDS-SDS. This leads to more molecular entanglement because DSF has no such crosslinked structures as TDS-SDS resulted from the protein re-polymerization and protein-carbohydrate Maillard reaction during thermo-chemical treatment. These results were also confirmed by the apparent viscosities measured in time mode (Figure 10B). Thus, the "TDS-SDS+EMPA" adhesive displayed a slow linear increase in viscosity, from 87 to 131 Pa.s, while the "DSF+EMPA" adhesive exhibited a sharp exponential increase, from 2101 to 1404 Pa.s, at the same shear rate $\left(10 \mathrm{~s}^{-1}\right)$ at $25^{\circ} \mathrm{C}$ for $40 \mathrm{~min}$. The shear rate in the time-mode test was selected because it is comparable to the common roller rotating rate (400-800 rpm) of an adhesive spreader in commercial plywood production. Because the adhesive load on the veneer is highly correlated to the adhesive viscosity, the slow increase in apparent viscosity indicated that the "TDS-SDS+EMPA" adhesive displayed better viscosity stability than the "DSF+EMPA" adhesive. Thus, the former adhesive was more beneficial to the stabilization of plywood production. 

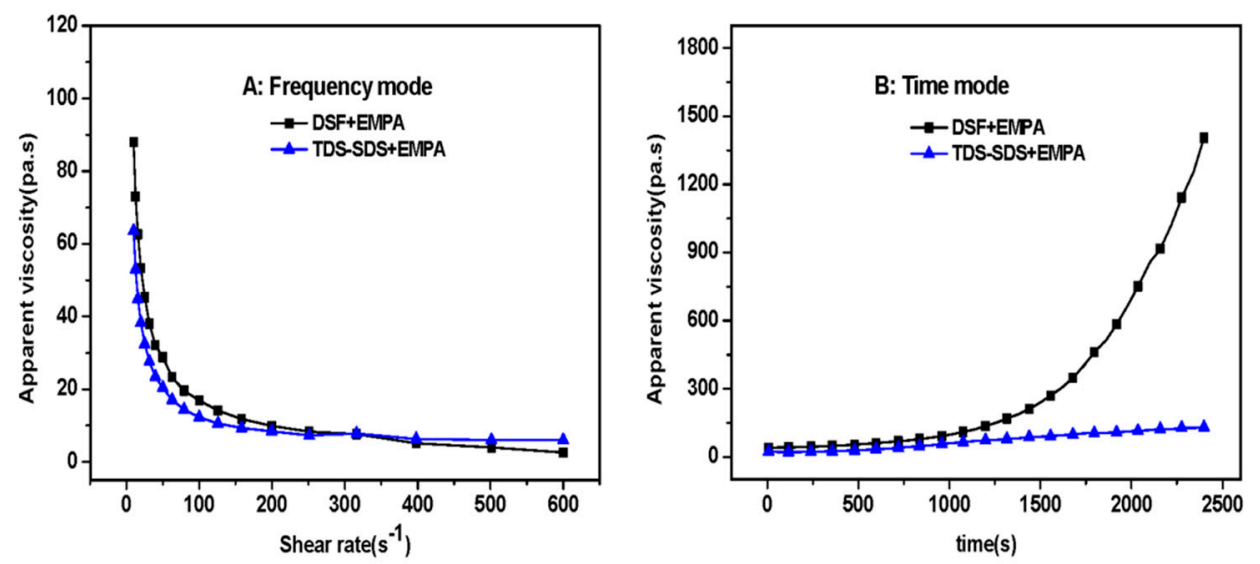

Figure 10. Apparent viscosity of various DSF-based adhesives, frequency mode (A) and Time mode (B).

\section{Conclusions}

A DSF-based adhesive with good water resistance and low viscosity was developed, which comprised thermo-chemical treatment of DSF in the presence of SDS at $140{ }^{\circ} \mathrm{C}$ followed by crosslinking modification with EMPA. Because of the destruction of hydrophobic moieties and inhibition of macromolecular aggregation by SDS, the thermo-chemically treated DSF released more reactive groups. This aided protein repolymerization, rearrangement of the protein hydrophobic chains, the Maillard reaction between the protein and soybean carbohydrate, and the effective crosslinking reaction between DSF and EMPA. The formation of a more compact network structure led to the effective improvement in the water resistance of the "TDS-SDS+EMPA" adhesive. Thus, the proposed adhesive could withstand a $28 \mathrm{~h}$ boiling-dry-boiling hydrothermal treatment and maintain a wet-bond strength of $1.21 \mathrm{MPa}$, exceeding the required value for structural use $(0.98 \mathrm{MPa})$. However, the Maillard reaction during the thermo-chemical treatment of DSF is to be further evaluated delicately in order to effectively improve and/or tailor the bond performance of DSF-based adhesives.

Author Contributions: Conceptualization, B.Z.; Data curation, J.L. and J.G.; Funding acquisition, Z.G.; Investigation, B.Z.; Project administration, Z.G.; Software, Y.K. and Z.G.; Supervision, Z.G.; Writing-original draft, B.Z. and Y.Z.

Funding: This work was supported by the Fundamental Research Funds for the Central Universities (grant number 2572017EB06), the Chinese National Natural Science Foundation (grant number 31870542) and the National Undergraduate Training Programs for Innovations (grant number 201810225030).

Acknowledgments: Kind acknowledgment to Yanhua Zhang for her XPS analysis and Haiyan Tan for his assistance of plywood evaluation.

Conflicts of Interest: The authors declare no conflict of interest.

\section{References}

1. Bacigalupe, A.; Poliszuk, A.K.; Eisenberg, P.; Escobar, M.M. Rheological behavior and bonding performance of an alkaline soy protein suspension. Int. J. Adhes. Adhes. 2015, 62, 1-6. [CrossRef]

2. Haag, A.P.; Geesey, G.G.; Mittleman, M.W. Bacterially derived wood adhesive. Int. J. Adhes. Adhes. 2006, 26, 177-183. [CrossRef]

3. Zheng, P.; Lin, Q.; Li, F.; Ou, Y.; Chen, N. Development and characterization of a defatted soy flour-based bio-adhesive crosslinked by 1,2,3,4-butanetetracarboxylic acid. Int. J. Adhes. Adhes. 2017, 78, 148-154. [CrossRef]

4. Yuan, C.; Chen, M.; Luo, J.; Li, X.; Gao, Q.; Li, J. A novel water-based process produces eco-friendly bio-adhesive made from green cross-linked soybean soluble polysaccharide and soy protein. Carbohydr. Polym. 2017, 169, 417-425. [CrossRef] [PubMed]

5. Chen, N.; Lin, Q.; Rao, J.; Zeng, Q. Water resistances and bonding strengths of soy-based adhesives containing different carbohydrates. Ind. Crop. Prod. 2013, 50, 44-49. [CrossRef] 
6. Gao, Z.; Zhang, Y.; Fang, B.; Zhang, L.; Shi, J. The effects of thermal-acid treatment and crosslinking on the water resistance of soybean protein. Ind. Crop. Prod. 2015, 74, 122-131. [CrossRef]

7. Gui, C.; Wang, G.; Wu, D.; Zhu, J.; Liu, X. Synthesis of a bio-based polyamidoamine-epichlorohydrin resin and its application for soy-based adhesives. Int. J. Adhes. Adhes. 2013, 44, 237-242. [CrossRef]

8. Iman, M.; Bania, K.K.; Maji, T.K. Green jute-based cross-linked soy flour nanocomposites reinforced with cellulose whiskers and nanoclay. Ind. Eng. Chem. Res. 2013, 52, 6969-6983. [CrossRef]

9. Liu, D.; Chen, H.; Chang, P.R.; Wu, Q.; Li, K.; Guan, L. Biomimetic soy protein nanocomposites with calcium carbonate crystalline arrays for use as wood adhesive. Bioresour. Technol. 2010, 101, 6235-6241. [CrossRef] [PubMed]

10. Qi, G.Y.; Li, N.B.; Wang, D.H.; Sun, X.S. Physicochemical properties of soy protein adhesives obtained by in situ sodium bisulfite modification during acid precipitation. J. Am. Oil Chem. Soc. 2012, 89, 301-312. [CrossRef]

11. Zhang, Y.; Zhu, W.; Gao, Z.; Gu, J. Effects of crosslinking on the mechanical properties and biodegradability of soybean protein-based composites. J. Appl. Polym. Sci. 2015, 132. [CrossRef]

12. Hettiarachchy, N.; Kalapathy, U.; Myers, D. Alkali-modified soy protein with improved adhesive and hydrophobic properties. J. Am. Oil Chem. Soc. 1995, 72, 1461-1464. [CrossRef]

13. Huang, W.; Sun, X. Adhesive properties of soy proteins modified by sodium dodecyl sulfate and sodium dodecylbenzene sulfonate. J. Am. Oil Chem. Soc. 2000, 77, 705-708. [CrossRef]

14. Zhang, Y.; Zhu, W.; Lu, Y.; Gao, Z.; Gu, J. Water-resistant soybean adhesive for wood binder employing combinations of caustic degradation, nano-modification, and chemical crosslinking. Bioresources 2013, 8 , 1283-1291. [CrossRef]

15. Wang, Y.; Mo, X.; Sun, X.S.; Wang, D. Soy protein adhesion enhanced by glutaraldehyde crosslink. J. Appl. Polym. Sci. 2007, 104, 130-136. [CrossRef]

16. Gonzalez, A.; Cristina Strumia, M.; Alvarez Igarzabal, C.I. Cross-linked soy protein as material for biodegradable films: Synthesis, characterization and biodegradation. J. Food Eng. 2011, 106, 331-338. [CrossRef]

17. Deng, R.; Chen, Y.; Chen, P.; Zhang, L.; Liao, B. Properties and biodegradability of water-resistant soy protein/poly(epsilon-caprolactone)/toluene-2,4-diisocyanate composites. Polym. Degrad. Stabil. 2006, 91, 2189-2197. [CrossRef]

18. Gu, K.; Li, K. Preparation and evaluation of particleboard with a soy flour-polyethylenimine-maleic anhydride adhesive. J. Am. Oil Chem. Soc. 2011, 88, 673-679. [CrossRef]

19. Lei, H.; Du, G.; Wu, Z.; Xi, X.; Dong, Z. Cross-linked soy-based wood adhesives for plywood. Int. J. Adhes. Adhes. 2014, 50, 199-203. [CrossRef]

20. Tabarsa, T.; Jahanshahi, S.; Ashori, A. Mechanical and physical properties of wheat straw boards bonded with a tannin modified phenol-formaldehyde adhesive. Compos. Part B 2011, 42, 176-180. [CrossRef]

21. Park, B.D.; Lee, S.M.; Roh, J.K. Effects of formaldehyde/urea mole ratio and melamine content on the hydrolytic stability of cured urea-melamine-formaldehyde resin. Eur. J. Wood Wood Prod. 2009, 67, 121-123. [CrossRef]

22. Luo, J.; Luo, J.; Gao, Q.; Li, J. Effects of heat treatment on wet shear strength of plywood bonded with soybean meal-based adhesive. Ind. Crop. Prod. 2015, 63, 281-286. [CrossRef]

23. Zheng, P.; Li, Y.; Li, F.; Ou, Y.; Lin, Q.; Chen, N. Development of defatted soy flour-based adhesives by acid hydrolysis of carbohydrates. Polymers 2017, 9, 153. [CrossRef]

24. Zhang, B.; Fan, B.; Huo, P.; Gao, Z. Improvement of the water resistance of soybean protein-based wood adhesive by a thermo-chemical treatment approach. Int. J. Adhes. Adhes. 2017, 78, 222-226. [CrossRef]

25. Vnucec, D.; Kutnar, A.; Gorsek, A. Soy-based adhesives for wood-bonding-A review. J. Adhes. Sci. Technol. 2017, 31, 910-931. [CrossRef]

26. Zhang, B.; Fan, B.; Li, M.; Zhang, Y.; Gao, Z. Effects of thermal treatment on the properties of defatted soya bean flour and its adhesion to plywood. R. Soc. Open Sci. 2018, 5, 180015. [CrossRef] [PubMed]

27. Zhang, L.; Zhang, B.; Fan, B.; Gao, Z.; Shi, J. Liquefaction of soybean protein and its effects on the properties of soybean protein adhesive. Pigm. Resin Technol. 2017, 46, 399-407. [CrossRef]

28. Wang, Y.; Sun, X.S.; Wang, D. Effects of preheating treatment on thermal property and adhesion performance of soy protein isolates. J. Adhes. Sci. Technol. 2007, 21, 1469-1481. [CrossRef] 
29. Guo, J.; Yang, X.Q.; He, X.T.; Wu, N.N.; Wang, J.M.; Gu, W.; Zhang, Y.Y. Limited aggregation behavior of $\beta$-conglycinin and its terminating effect on glycinin aggregation during heating at PH 7.0. J. Agric. Food Chem. 2012, 60, 3782. [CrossRef] [PubMed]

30. Zhong, Z.K.; Sun, X.S.; Fang, X.H.; Ratto, J. Adhesion strength of sodium dodecyl sulfate-modified soy protein to fiberboard. J. Adhes. Sci. Technol. 2001, 15, 1417-1427. [CrossRef]

31. Fan, B.; Zhang, L.; Gao, Z.; Zhang, Y.; Shi, J.; Li, J. Formulation of a novel soybean protein-based wood adhesive with desired water resistance and technological applicability. J. Appl. Polym. Sci. 2016, 133. [CrossRef]

32. Li, K.; Peshkova, S.; Geng, X. Investigation of soy protein-kymene ${ }^{\circledR}$ adhesive systems for wood composites. J. Am. Oil Chem. Soc. 2004, 81, 487-491. [CrossRef]

33. Nooshkam, M.; Madadlou, A. Maillard conjugation of lactulose with potentially bioactive peptides. Food Chem. 2016, 192, 831-836. [CrossRef] [PubMed]

34. Friedman, M. Chemistry, biochemistry, and safety of acrylamide. A review. J. Agric. Food Chem. 2003, 51, 4504-4526. [CrossRef] [PubMed]

35. Mottram, D.S.; Wedzicha, B.L.; Dodson, A.T. Food chemistry: Acrylamide is formed in the maillard reaction. Nature 2002, 419, 448-449. [CrossRef] [PubMed]

36. Wang, Z.; Li, Y.; Jiang, L.; Qi, B.; Zhou, L. Relationship between secondary structure and surface hydrophobicity of soybean protein isolate subjected to heat treatment. J. Chem. 2014, 2014, 475389. [CrossRef]

37. Drummy, L.F.; Phillips, D.M.; Stone, M.O.; Farmer, B.L.; Naik, R.R. Thermally induced alpha-helix to beta-sheet transition in regenerated silk fibers and films. Biomacromolecules 2005, 6, 3328-3333. [CrossRef] [PubMed]

38. Meng, G.; Ma, C.Y. Characterization of globulin from Phaseolus angularis (red bean). Int. J. Food Sci. Technol. 2002, 37, 687-695. [CrossRef]

39. Li, H.; Li, C.; Gao, Q.; Zhang, S.; Li, J. Properties of soybean-flour-based adhesives enhanced by attapulgite and glycerol polyglycidyl ether. Ind. Crop. Prod. 2014, 59, 35-40. [CrossRef]

(C) 2018 by the authors. Licensee MDPI, Basel, Switzerland. This article is an open access article distributed under the terms and conditions of the Creative Commons Attribution (CC BY) license (http:/ / creativecommons.org/licenses/by/4.0/). 